\title{
FISH-OIL PRECONDITIONING UP-REGULATES EXPRESSION OF SPLENIC ARG1 POSITIVE M2 TYPE MACROPHAGES AND THE ARG1/INOS2 RATIO AFTER EXPERIMENTAL INDUCED TRANSIENT CEREBRAL ISCHEMIA
}

\author{
EMÖKE HORVÁTH $^{1}$, ALEX ORĂDAN ${ }^{2}$, LIVIU CHIRIAC ${ }^{3,4}$, MINODORA DOBREANU $^{5,6}$, \\ ELÖD-ERNÖ NAGY ${ }^{7}$, SEPTIMIU VOIDĂZAN ${ }^{8}$, ROBERT BEREI ${ }^{9}$, DANIELA LUCIA \\ MUNTEAN $^{10}$, ADINA HUT,ANU ${ }^{5,6}$ \\ ${ }^{I}$ Department of Pathology, University of Medicine, Pharmacy, Science and Technology, 38 Gh. Marinescu Street, Târgu \\ Mureș, Romania \\ ${ }^{2}$ Laboratory Animal Facility-Centre for Experimental Medicine, "Iuliu Hațieganu” University of Medicine and Pharmacy, 6 \\ Louis Pasteur Street, Cluj-Napoca, Romania \\ ${ }^{3}$ National Magnetic Resonance Centre, Faculty of Physics, "Babeș-Bolyai” University, 1 Mihail Kogălniceanu Street, Cluj- \\ Napoca, Romania \\ ${ }^{4}$ Department of Molecular Sciences, Faculty of Medicine, "Iuliu Hațieganu” University of Medicine and Pharmacy, 6 Louis \\ Pasteur Street, Cluj-Napoca, Romania \\ ${ }^{5}$ Centre for Advanced Medical and Pharmaceutical Research, University of Medicine, Pharmacy, Science and Technology, \\ 38 Gh. Marinescu Street, Târgu Mureș, Romania \\ ${ }^{6}$ Department of Laboratory Medicine, University of Medicine Pharmacy, Science and Technology, 38 Gh. Marinescu Street, \\ Târgu Mureș, Romania \\ ${ }^{7}$ Department of Biochemistry, University of Medicine, Pharmacy, Science and Technology, 38 Gh. Marinescu Street, Târgu \\ Mureș, Romania \\ ${ }^{8}$ Department of Epidemiology, University of Medicine, Pharmacy, Science and Technology, 38 Gh. Marinescu Street, Târgu \\ Mureș, Romania \\ ${ }^{9}$ Faculty of General Medicine, University of Medicine, Pharmacy, Science and Technology, 38 Gh. Marinescu Street, Târgu \\ Mures, Romania \\ ${ }^{10}$ Department of Analytical Chemistry and Drug Analysis, University of Medicine, Pharmacy, Science and Technology, 38 \\ Gh. Marinescu Street, Târgu Mureș, Romania
}

*corresponding author: emoke.horvath@umfst.ro

\begin{abstract}
During a stroke, the contraction of the spleen can mobilize inflammatory cells that infiltrate the damaged brain tissue. We analysed the effects of transient cerebral ischemia and fish oil preconditioning on the spleen volume, architecture, and macrophage polarization. Wistar rats were subjected to middle cerebral artery occlusion (ischemic and treatment groups, each $\mathrm{n}=10)$, and were sacrificed after $24 \mathrm{hrs}$, along with a sham group $(\mathrm{n}=10)$. The spleen volume suffered only mild variations, while the marginal zone showed size reduction in the ischemic group, compared to treated and control groups. Granulopoiesis and myeloperoxidase positivity were significantly increased in spleens of ischemic animals $(\mathrm{p}<0.001 v s$. the treatment and sham groups). Arginase 1 was up-regulated and the Arg1/iNOS2 expression ratio showed a significant shift on macrophages of marginal zone/red pulp interface in the treatment group compared to ischemic rats $(\mathrm{p}<0.001)$. Arg1 positive M2 type monocytes/macrophages participate in resolution and tissue repair thus may feature as potential therapeutical targets in cerebral ischemia.
\end{abstract}

\section{Rezumat}

În ischemia cerebrală acută, contracția splinei mobilizează celule inflamatorii care infiltrează teritoriul lezat. Am analizat efectele ischemiei cerebrale tranzitorii și a precondiționării cu ulei de pește asupra variațiilor de volum, arhitectură și polarizare a macrofagelor în splina de șobolani Wistar randomizați în grup ischemic și tratat $(\mathrm{n}=10$ fiecare), supuși ocluziei arterei cerebrale medii, sacrificați după 24 ore, împreună cu un grup control. Volumul splenic a suferit variații moderate, în timp ce zona marginală a scăzut în diametru la grupul ischemic în comparație cu cel tratat și control. Granulopoieza și expresia mieloperoxidazei a crescut semnificativ în splina animalelor cu ischemie față de cele tratate şi control $(p<0,001)$. Expresia arginazei 1 și raportul expresiei Arg1/iNOS2 la nivelul macrofagelor din interfaţa zonei marginale/pulpă roșie s-a deplasat în favoarea grupului tratat față de cel ischemic $(\mathrm{p}<0,001)$. Deoarece macrofagele/monocitele Arg1 pozitive participă în rezoluție și reparație tisulară, pot fi ținte terapeutice în atacul ischemic cerebral.

Keywords: transient middle cerebral artery occlusion, spleen macrophages, arginase 1, Arg1/iNOS2 ratio 


\section{Introduction}

Focal and global cerebral ischemias represent catastrophic events with high morbidity and mortality in industrialized countries due to irreversible neurological and cognitive deficits without satisfactory therapies [36]. In this context, prevention represents a public health priority focused on the protection of the brain tissue components (both neurons and the neurovascular unit). The ischemic neuronal damage features various pathways, like anoxic depolarization, perturbed glutamatergic neurotransmission and intracellular calcium signalling and excessive formation of reactive oxygen species [7]. This complex process activates the local microglia that launches chemotactic signals generating a significant infiltration of peripheral immune cells into the damaged area $[15,19]$.

The consequences of acute brain ischemic injury extend far beyond the brain: the activation of the sympathetic nervous system results in splenic contraction and a potential liberation of red and white blood cells [41]. These phenomena are associated with a strong response from the peripheral immune system, consisting of cytokine release (e.g. IFN- $\gamma$ ) and a robustious macrophage, neutrophil, and lymphocyte efflux. These cells can be tracked by carboxyfluorescein diacetate succinimidyl ester (CFSE) labelling, they flow out to the systemic circulation and as a consequence their number is significantly reduced after 24 - 48 hours in the spleen [30]. In a clinical study, approximately $40 \%$ of patients showed splenic contraction, African Americans, the elderly and those with stroke history having higher odds to express this process [37].

The released pro-inflammatory cytokines promote a secondary response in the brain contributing to amplification of neural tissue damage [2].

Splenectomy proved to be beneficial in many rodent models concerning the output of cerebral ischemia, but the nature of the protection is actually incompletely understood. The removal of the spleen in rats, before middle cerebral artery occlusion, decreased significantly the infarction volume in the brain compared with animals that were subjected to middle cerebral artery occlusion (MCAO) without splenectomy. Also, the number of infiltrating macrophages and T-lymphocytes, along with levels of circulating pro-inflammatory cytokines were more reduced in the first group $[1,8,42]$.

Omega-3 polyunsaturated fatty acids (n-3 PUFAs), major components of dietary fish oil (FO), are known to protect against ischemic brain damage in multiple animal models [9, 11, 27, 43]. For this reason, the potential of n-3 PUFAs was assessed for stroke prevention and treatment. As major components of neuronal membranes, n-3 PUFAs are characterized by a broad spectrum in terms of neuroprotection. They have regulatory and anti-inflammatory effects, influencing synaptic plasticity and blunting the microglia-mediated oxidative stress along with lipid-peroxidation suppression functions [4, 12, 28]. n-3 PUFAs can trigger postischemic revascularization by angiogenesis in the ischemic penumbra and stimulate proliferation of neural stem cells, migration of neuroblasts, enhancing oligodendrogenesis and white matter recovery [44]. The protective role of docosahexaenoic acid (DHA) in neuroinflammation was demonstrated not only in preventive treatment schedules but also in post-stroke therapy. Following ischemic injury, a 3-month DHA treatment prevented microglial activation; significantly reduced the ischemic lesion size and the levels of COX-2, IL-1 $\beta$, and IL-6 pro-inflammatory cytokines, increasing in parallel the levels of the anti-apoptotic molecule Bcl-2 in the brain [22].

A beneficial role of n-3 PUFAs was demonstrated also in cardiovascular and metabolic diseases, agerelated brain dysfunctions including recurrent affective disorders $[11,13,25,31]$ and attention deficit hyperactivity disorder in children [35]. Consecutively, prophylactic or therapeutic supplementation with n-3 PUFAs represents a highly promising neuroprotective strategy in a variety of neurological disorders.

Based on our preliminary results regarding characterization of the inflammatory infiltrate in the damaged brain tissue and plasma cytokines profile after transient middle cerebral artery occlusion (tMCAO) $[16,18]$, we hypothesized, that the degree of tissue injury in experimental cerebral ischemia can be associated by complex histopathological changes, not only in the brain but also in the spleen. In the current work, we focused on splenic responses in ischemia/reperfusion, splenic volume variation, and architectural changes. A special objective was the detection of pro-inflammatory (M1) and anti-inflammatory (M2) monocyte/macrophage subsets in histological regions corresponding to highly reactive cellular pools, in animals with and without FO protection.

\section{Materials and Methods}

The experimental protocol was approved by the Ethics Committee of the Pharmacy, Science and Technology (Ethical Committee approval number: 17/17.03.2016) and was carried out in accordance with the European Union Directive of September 22, 2010 (2010/63/EU). All efforts were made to avoid animal suffering and keep to a minimum the number of animals. The experimental procedure is illustrated in Figure 1. 


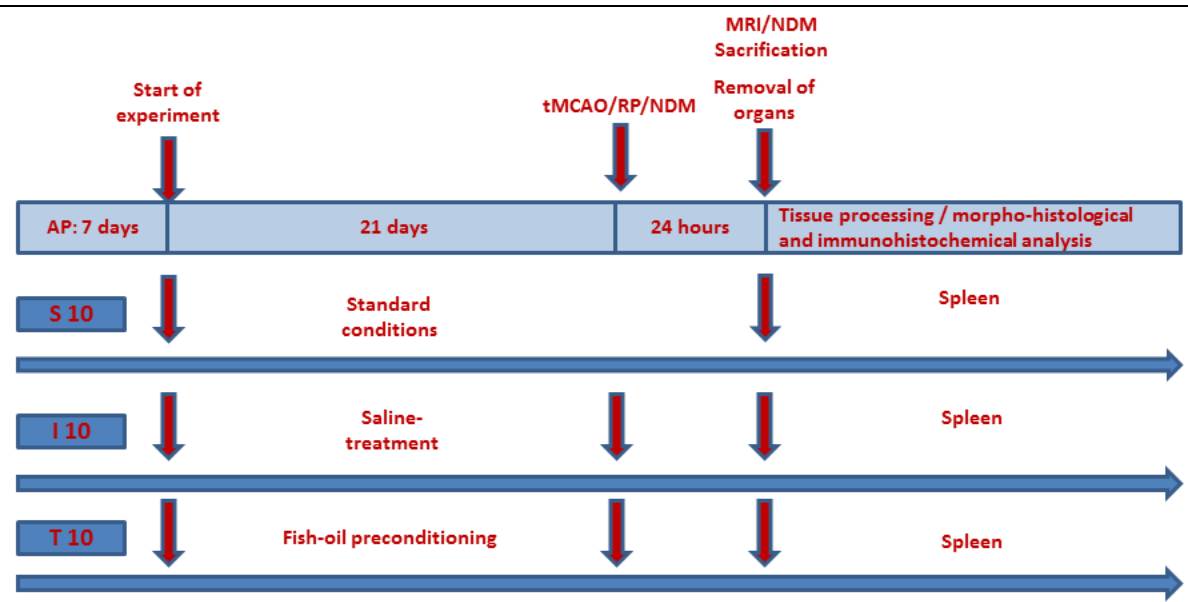

S: sham group

I: saline-treated group

$T$ : fish-oil treated group
AP: accommodation period

tMCAO: transient middle cerebral artery occlusion

RP: reperfusion

MRI: magnetic resonance imaging

MRI: magnetic resonance imaging

Figure 1.

Timeline graph of the experimental design

\section{Animals and treatment}

Initially, 30 healthy Wistar male adult rats from the Animal Facility of the "Iuliu Hațieganu" University of Medicine and Pharmacy, Cluj-Napoca, Romania, were included in the study. All rats were in good nutritional status (280 - $330 \mathrm{~g})$ and were divided by simple randomization into a sham group (S), salinetreated ischemic group (I), and highly purified fishoil (FO) phospholipid emulsion preconditioning group (T), with 10 animals each. Laboratory conditions and the treatment algorithm have been described in detail in our previous work [18]. In summary, $\mathrm{T}$ group specimens were treated daily with a phospholipid emulsion 21 days before tMCAO administered intraperitoneally in a dose of $3.5 \mathrm{~mL} / \mathrm{kg}$ bw/day, corresponding to a concentration of $70 \mathrm{mg} / \mathrm{kg}$ bw eicosapentaenoic acid (EPA) and $80 \mathrm{mg} / \mathrm{kg}$ bw docosahexenoic acid (DHA). In placebo-treated animals (I), the same volume of saline solution $(0.9 \% \mathrm{NaCl})$ was i.p. administered. The animals' weight was recorded weekly throughout the study.

Unilateral tMCAO and reperfusion in rats

After 21 days, in I and T groups, transient focal brain ischemia was achieved during MCAO surgery, using the intraluminal filament technique. The surgical method, anaesthesia, preoperative and postoperative monitoring conditions and the measurement of the cerebral infarction volume were performed as described in a previous study [26].

Briefly, all groups were subjected to anaesthesia (3.5\% isoflurane for induction and $1.5 \%$ for maintenance) and surgical procedure in order to prepare the carotid bifurcation and to occlude the left middle cerebral artery (MCA). Reperfusion was initiated after 90 min by removal of the filaments. Postoperative pain was reduced by subcutaneous administration of tramadol.
The ischemic conditions created by MCAO have been validated by neurological deficit measurement and brain MRI examination. Two animals from the ischemic group (I1 and I4) died in the post-ischemic/reperfusion period, one animal (I3) had a negligible ischemic volume on MRI examination, consequently, they were excluded from the histological study. At the end of the experimental period, after 24 hours all 27 eligible animals were sacrificed.

Tissue preparation

For the assessment of the morphological changes, immediately after MRI and neurological control, the rats were sacrificed under deep anaesthesia by isoflurane overdose. After installation of death (confirmed by the veterinarian based on the absence of vital functions, limb, and corneal reflexes), the animals were perfused with $20 \mathrm{~mL}$ of $10 \%$ formalin through the left ventricle; the spleens were removed, washed in physiological saline and kept $24 \mathrm{~h}$ in $10 \%$ neutral buffered formalin for further processing.

Morphological characterization of the spleen

To determine the organ volume, each spleen was measured individually and their histological structures were examined. The spleen volumes were calculated with the specific mathematical formula:

$$
\mathrm{V}=\mathrm{W} \times \mathrm{T} \times \mathrm{L} \times \pi / 6,
$$

where $\mathrm{V}$ is the ellipsoid volume, $\mathrm{L}$ the length, $\mathrm{T}$ the thickness (both in the sagittal plane), and $\mathrm{W}$ represents the width in the transverse plane [33].

Histological analysis and immunohistochemistry Subsequently, the spleens sectioned into two equal parts in the sagittal plane were processed according to standard histology, procedures serial sections of 4 - $5 \mu \mathrm{m}$ width being performed. One section was stained with $H \& E$, additional sections were performed 
for immunohistochemical analysis: incubation with DAKO EnVision FLEX Peroxidase-Blocking Reagent for 15 minutes, antigen retrieval in citrate solution (pH 6) in a microwave oven, washing and incubation with anti-myeloperoxidase (MPO) antibody, clone NCLMYELO, dilution 1:100 (Novocastra Laboratories), anti-inducible nitric oxide synthase (iNOS2), clone AA1-50, dilution 1:100 (Bioss Antibodies), polyclonal anti-Arginase, Liver (Arg1), dilution 1:200 (Bioss Antibodies) for 24 hours in a wet chamber at 4 . As a secondary antibody, we used EnVision ${ }^{\mathrm{TM}}$ FLEX/HRP (Dako) in combination with a 3,3'-diaminobenzidine (DAB) solution for the chromogenic identification of the above-mentioned antigens. Nuclei were visualized by haematoxylin counterstaining. All the morphological analyses were performed by a pathologist.

\section{Quantitative digital morphometry}

Both the H\&E and immunostained slides were digitally scanned at 20X magnification with Mirax Scanner and examined with the associated Panoramic Viewer 1.15.4 software (3DHISTECH Ltd., Budapest, Hungary) using $20 \mathrm{X}$ magnification. For quantification of the extramedullary haematopoiesis, and characterization of M1 and M2 macrophage subtypes in the borderline of red pulp, five representative foci being chosen from each case, captured with a $20 \mathrm{X}$ objective and. MPO, iNOS2, Arg1 positive cell count and total positive surface area (percent of DAB immunolabeled cells) were measured with the image analysis software Image J 1.46 (National Institutes of Health, Bethesda, MD, USA) using HSB (hue, saturation, brightness) colour filtering. The microscopic examination has been focused on the parallel evaluation of pre-existing nodular lymphoid structures (splenic lymphoid follicles, marginal zones, periarterial lymphoid sheaths) and red pulp in all three groups. In order to determine the extension of the white pulp (maximal diameter), a representative area with at least five lymphoid tissue organized around central arterioles was captured with the $5 \mathrm{X}$ objective. We measured the maximum diameter of 5 lymphoid structures, specifying the extension of the marginal zone for each case (Figure 2). The results were calculated individually for each case based on the arithmetic mean. All parameters were analysed and assessed individually by two investigators; if necessary, the discrepancies of their findings were discussed, and a consensus was reached.

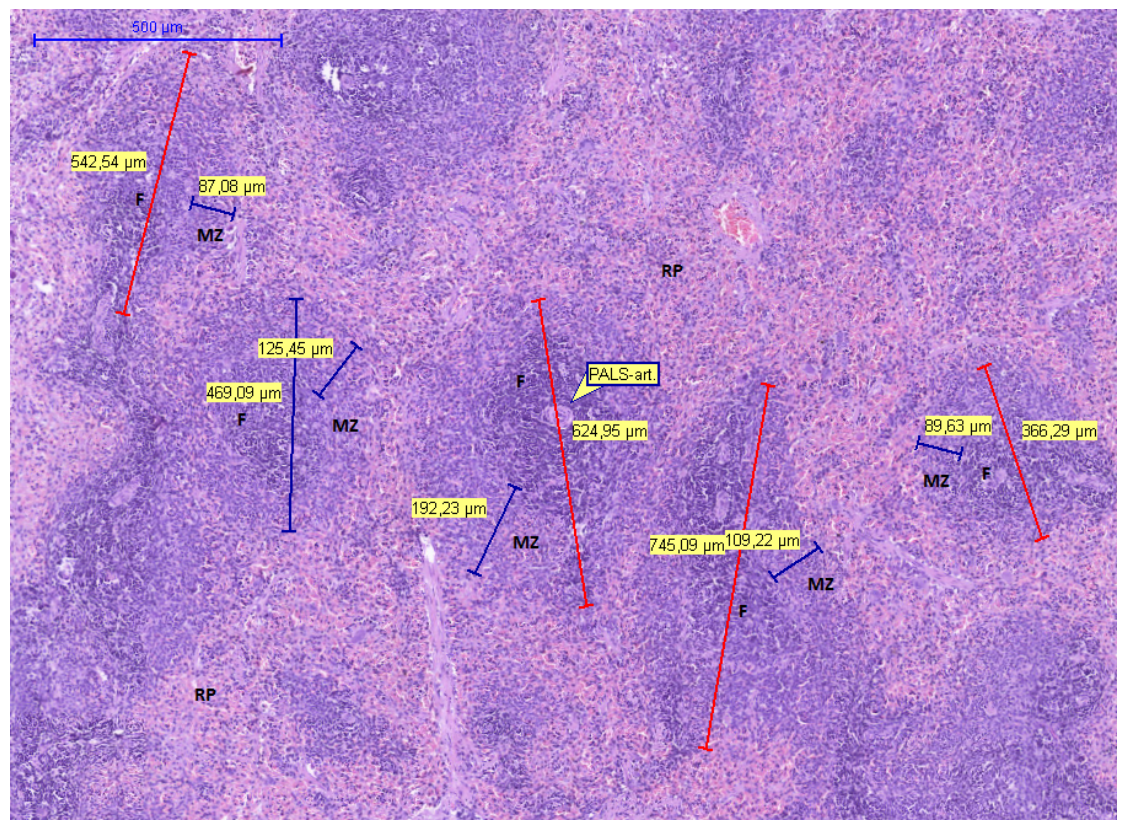

Figure 2.

Cross-sections of the adult male rats' spleens (H\&E stain). Representative image for quantitative analysis of splenic white pulp. $1.5 \mathrm{X}$ magnification highlights five marked secondary follicles (F) with surrounding marginal zones (MZ) and periarteriolar lymphoid sheaths (PALS)

\section{Statistical analysis}

Statistical analysis was performed using the Graph Pad Prism 7.01 Software. As some of the parameters showed non-gaussian distribution, non-parametric tests were applied for comparison of multiple groups (the Kruskal-Wallis ANOVA and Mann-Whitney U test, respectively). Consequently, values were represented as median with 25 - 75 percentile or 95 CI range.
The threshold of statistical significance has been set to $\mathrm{p}<0.05$.

\section{Results and Discussion}

Animals were rigorously monitored during the experiment. The animals' weight showed small oscillations, however, no significant differences were found during the treatment weeks among the three groups and no 
FARMACIA, 2019, Vol. 67, 5

significant differences in physiological variables were registered.

tMCAO-induced effects on spleen volume

24 hours after tMCAO the spleen volume ranged between 489 (452 - 509) (group I), 525 (501 - 544) (group T) and $510(408-535)$ (group S) $\mathrm{mm}^{3}$. The

overall variance was not significant $(p=0.202)$, the highest values being obtained at group $\mathrm{T}$, with a borderline difference between the $\mathrm{T}$ and $\mathrm{S}$ groups $(p=0.055)$. If we normalized the splenic volumes with weight $\left(\mathrm{mm}^{3} / \mathrm{g}\right)$, neither the overall nor the between group differences were significant (Table I).

Table I

Histo-morphological variables in the studied groups Ischemic group $(n=7) \quad$ Treatment group $(n=10)$

\begin{tabular}{lccc}
\multicolumn{1}{c}{ Variables } & Sham group $(\mathbf{n}=\mathbf{1 0})$ & Ischemic group $(\mathbf{n}=\mathbf{7})$ & Treatment group $(\mathbf{n}=\mathbf{1 0})$ \\
\hline Spleen volume $\left(\mathbf{m m}^{3}\right)$ & $510(408-535)$ & $489(452-509)$ & $525(501-544)$ \\
Spleen volume, normalized & $1.63(1.46-1.75)$ & $1.7(1.46-1.78)$ & $1.8(1.59-1.89)$ \\
White pulp diameter $(\boldsymbol{\mu m})$ & $591(573-613)$ & $574(550-598)$ & $581(543-675)$ \\
Marginal zone diameter $(\boldsymbol{\mu m})$ & $101.4(97.3-105.7)^{* *}$ & $85(82-90)^{* *, \prime \prime}$ & $103.4(81.4-118.4)^{\prime \prime}$ \\
\hline
\end{tabular}

Values expressed as median and percentiles $(25-75), * *, " p<0.01$

Qualitative histomorphologic evaluation of splenic tissue alterations

The histopathological examination based on $\mathrm{H} \& \mathrm{E}$ staining revealed preserved histological structures of the white pulp in animals of the sham group, welldefined follicles with prominent germinal centres and clearly demarcated marginal zone from the red pulp (Figure 3A). The both $\mathrm{T}$ and I groups, spleens showed tissue alterations compared with sham-operated subjects; however, no morphological discrepancies were detectable between the FO treated animals and group I subjects. Microscopy with low magnification showed depletion of the white pulp, blurry-edged splenic lymphoid follicles possessing unclear borders without wellestablished germinal centres and a tendency to confluence (Figure 3B). The red pulp highlighted collapsed venous sinuses with relatively few erythrocytes in comparison with the S groups' organs. The extra-medullary normoblastic haematopoiesis was more pronounced in the $\mathrm{T}$ and the I group spleens than in controls, being dominated by myeloid cells (myeloid hyperplasia) (Figure 3C), compared to the $\mathrm{S}$ group rats' spleens, where haematopoiesis was represented only by small foci including myeloid and erythropoietic cell aggregates and megakaryocytes.

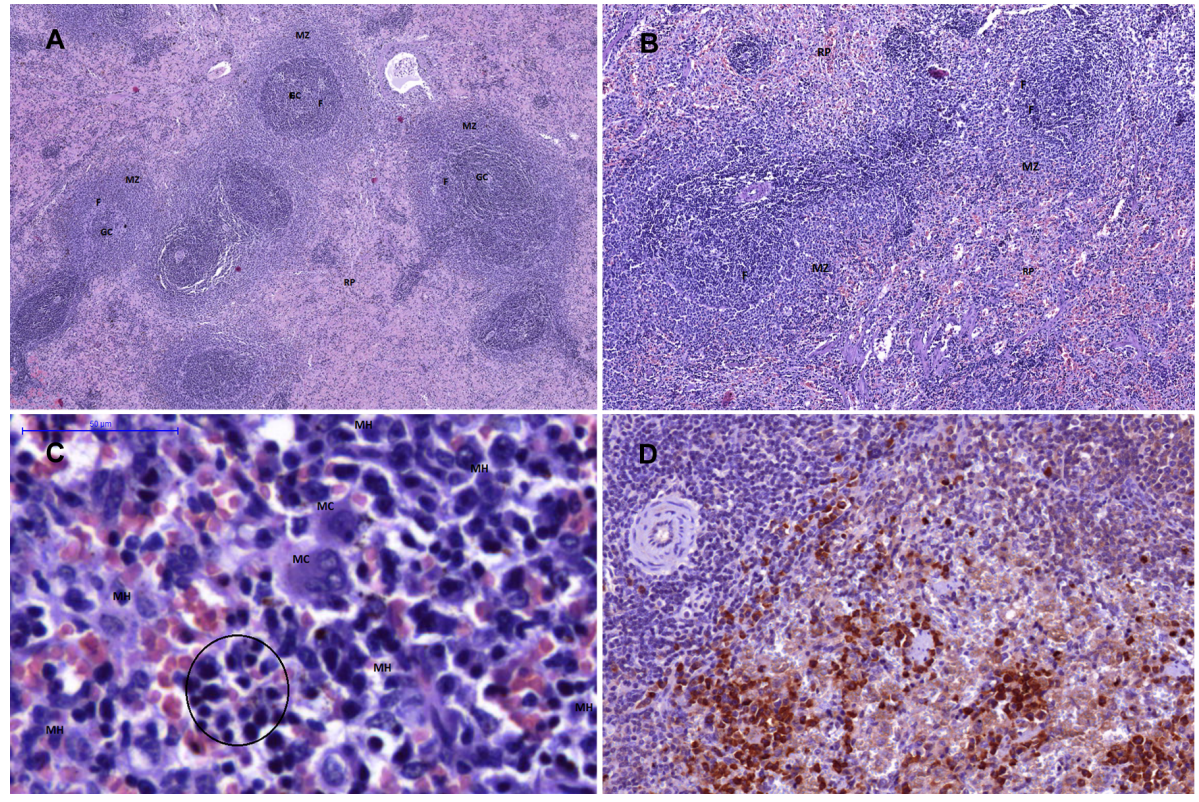

Figure 3.

Relative to the sham-group specimens (A, 1.5 X), the FO-treated and placebo-treated rat spleens show similar morphology: depletion of white pulp with blurry-edged splenic lymphoid follicles $(\mathrm{F})$ with unclear borders without well-established germ centres (GC) and their tendency to confluence. The red pulp highlighted collapsed venous sinuses with relatively few erythrocytes $(\mathrm{B}, 5 \mathrm{X})$. In the $\mathrm{T}$ and I group spleens increased extra medullary normoblastic haematopoiesis it can be noted, dominated by large foci of granulopoietic cells (myeloid hyperplasia-MH) and aggregates of megacaryocytes (MC). The erythroid lineage (circle) are underrepresented $(\mathrm{C}, 40 \mathrm{X})$. These granulopoietic cells being quantifiable based on myeloperoxidase expression (D, DAB chromogen, $20 \mathrm{X}$ ) 
Quantitative structural changes in the spleen

Analysing the white pulp by digital morphometry, the normal nodularity of this zone presented overt variations, but the diameters did not differ significantly. With regard to the marginal zone, this showed a significant overall variance $(\mathrm{p}=0.033)$, both the $\mathrm{T}$ and $\mathrm{S}$ groups possessing larger diameters than the I group, with significant discrepancies: $103(81-118)$ and $101(97-106) v s .85(82-90)(\mathrm{p}=0.0011$ and $\mathrm{p}=0.0012$, Table I).

Immunohistochemical analysis

Since the red pulp is a blood filter that serves as a gate for many activated cells of the spleen, we examined the red pulp-marginal zone interface in order to assess the presence of activated monocytes/macrophages and the variations of extra-medullary granulocytic lineage.
tMCAO up-regulates the splenic extra-medullary granulocytic lineage

In order to characterize the extra-medullary myeloid cells in our groups, we used a marker with high specificity: MPO (Figure 3D). The image analysis showed, that MPO positive cells surface area was significantly lower in the sham and treatment groups than in the I group. In both cases, the difference was significant $(\mathrm{p}<0.001$.) MPO expression in the control and FOtreated groups was very similar $(\mathrm{p}=0.811)$.

Splenic M1 type monocytes/macrophages show highlevel expression in acute cerebral ischemia In the first $24 \mathrm{~h}$ after tMCAO, iNOS2 positive M1 type cells were detectable in all three groups. iNOS2 expression was the highest in the I group (Figure 4A), and lower in the $\mathrm{S}$ and $\mathrm{T}$ groups (Figure 4B), with a significant difference between I and S, respectively I and $\mathrm{T}$ (both $\mathrm{p}<0.001$ ). There was no difference between the control and FO-treated animals $(\mathrm{p}=0.541)$.

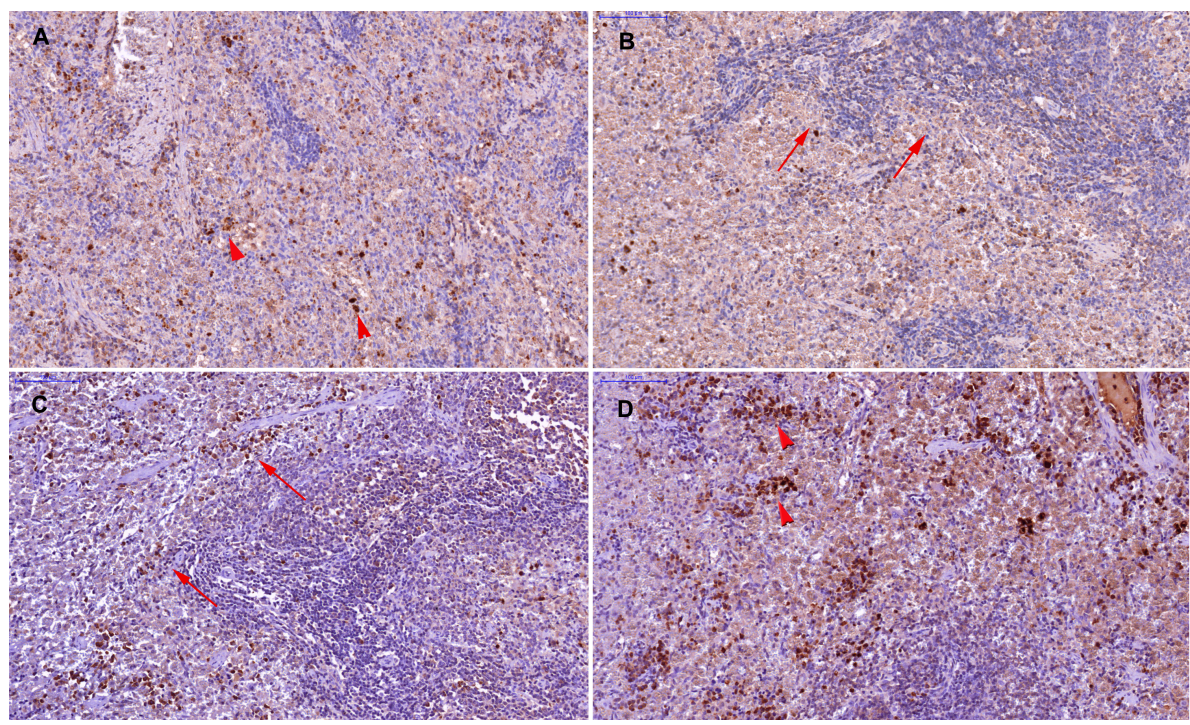

Figure 4.

Accumulation of iNOS2 and Arg1-positive macrophages (arrow heads) in red pulp-white pulp interface (arrows), $10 \mathrm{X}$ magnification, DAB chromogen. iNOS2 shows a stronger expression in the ischemic group (A) in comparison with FO-treated group (B). Arg1 positive macrophages are fewer in ischemic group (C), showing a numerical growth, forming even aggregates in the spleens of FO- treated animals (D).

Table II

Variations of extra-medullary granulopoiesis and immunological profile of macrophages, as positive surface area, in spleens of sham (S), ischemic (I) and FO-treated (T) groups

\begin{tabular}{|c|c|c|c|}
\hline Variables & $S$ group $(n=10)$ & $I \operatorname{group}(n=7)$ & $T \operatorname{group}(n=10)$ \\
\hline Myeloperoxidase (MPO) & $1.85(1.76-2.13)^{* * *}$ & $3.55(3.38-3.88)^{* * *}$ & $1.95(1.44-2.16)$ \\
\hline Inducible nitric oxide synthase (iNOS2) & $0.91(0.83-1.22)^{* * *}$ & $2.11(1.62-2.36)^{* * *, " ' "}$ & $1.02(0.86-1.15)^{\prime \prime \prime}$ \\
\hline Arginase 1 (Arg1) & 2.17 (1.64 - 2.57)€ & $1.76(1.23-2.53)^{\prime \prime}$ & $2.77(2.60-3.13) E^{\prime \prime}$ \\
\hline Arg1/iNOS2 & $2.18(1.42-2.74)^{* *}$ & $0.87(0.67-1.29)^{* *,} " '$ & 2.99 (2.36 - 3.22) "' \\
\hline
\end{tabular}

FO preconditioning triggers increased expression of Argl positive M2 type monocytes/macrophages

The Arg1 positive surface showed an opposite distribution to the iNOS2 marked zones among the three groups, being increased in FO-treated animals (T) and controls
(S) (Figure 4D) compared to the placebo-treated (I) group (Figure 4C). The difference was significant in both cases $(p=0.0014$ and $p=0.011$, respectively). Concerning the Arg1-iNOS2 positive surface ratio, the $\mathrm{S}$ and $\mathrm{T}$ groups showed a shift in favour of the 
FARMACIA, 2019, Vol. 67, 5

M2 cell subtype; unlike the I group, where the M1 phenotype was dominant. The Arg1/iNOS2 positive surface ratio was significantly higher in the $\mathrm{S}$ and $\mathrm{T}$ groups than in ischemic animals ( $p<0.01$ and $p<0.001$, respectively), with no difference between the former two (Figure 5). The results of the immunohistochemical analysis are summarised in Table II.

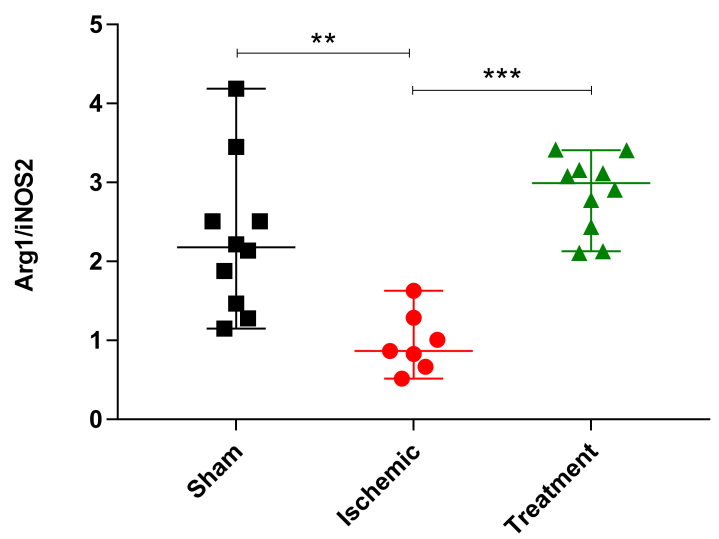

Figure 5.

Arginase (Arg1) and inducible nitric oxide synthase (iNOS2) expression in the splenic tissue. Comparative dot-plot representations of median scores and $95 \%$

CI values of Arg1/iNOS2 expression ratio in the examined groups. $* *<0.01, * * * \mathrm{p}<0.001$, calculated by the Mann-Whitney U test.

It is known, that brain ischemic injury triggers instantly the activation of the peripheral immune system with massive mobilization of immune cells into the circulation. In the central nervous system, these cells contribute significantly to stroke progression or impaired tissue repair. In this context, the spleen, as the largest natural reservoir of immune cells, represents a potential target for stroke treatment [23]. Shortly after an ischemic insult, the brain-spleen axis is activated by the sympathetic nervous system, chemotactic cytokines, and enhanced antigen presentation driven from the damaged brain [37]. Once activated, the spleen contracts, leading to discrete changes in spleen architecture and cellular alterations, and a transient decrease in spleen size that corresponds to splenocyte release into the systemic circulation [30].

Although several studies have investigated the correlation between stroke-induced cerebral tissue damage and activation of the splenic immune cells [2, 21, 42], only a few researchers have focused on the effects of $n-3$ polyunsaturated fatty acids on the spleen volume variation and tissue morphology following acute cerebral ischemia [34]. To explore the protective effect of n-3 PUFAs in rats submitted to tMCAO, we proposed a complex histological assessment of splenic compartmentalization and characterization of extra-medullary haematopoiesis. The majority of literature evidences describe that animals subjected to middle cerebral artery occlusion (MCAO) show a time-dependent variation after ischemia at 24 - 96 hours post-MCAO with significant reduction of their spleen weight due to the activation of $\alpha 1$ adrenergic receptors by catecholamine release, causing a contraction of the smooth muscles laying in the splenic capsule $[2,30]$. In our model, we showed a slightly decreased volume in the ischemic group in comparison with the FO-treated group, but the difference did not reach the threshold of significance, especially when we normalized the splenic volumes with body weight. This discrepancy may reflect the complexity and dynamism of splenic responses during the course of cerebral ischemia. Since we did not follow the dynamics of volume change and focused on the results of the first 24 hours following the procedure, we consider that the mild volume variation is attributable to the histological characteristics of the spleen capsule of rats. While the decrease of the splenic volume after stroke in humans happens due to smooth muscle contraction, the spleen of rodents does not contract as rapidly due to a relatively reduced number of smooth muscle cells in the capsule [6]. In our experiment, the morphological analysis of the target organ has revealed that the immediate effects of tMCAO are not limited only to cerebral tissue, important structural changes were detected in the spleen. A strong correlation between post-stroke activation of the immune system and changes in spleen tissue morphology has been described in animal models [3, 17, 41]. As an undescribed result, we report that these morphological changes characterize predominantly the splenic tissue of the ischemic group, being less evident in animals treated with fish oil/n-3 PUFAs. Due to its distinct white pulp components, the rat spleen is eligible for morphometric studies. It has a large and uniform marginal zone (an interface between the red pulp and the periarteriolar lymphoid sheath, follicles comprising up to $28 \%$ of the splenic volume). The pronounced marginal sinus delimits the marginal zone from the PALS and follicles, which are well demarcated. The red pulp contains extramedullary hematopoietic foci in physiologic conditions with any combination of erythroid, myeloid and megakaryocytic cells [6]. For these reasons, to more accurately characterize these changes in the spleen structure, we chose a combined qualitative and quantitative (morphometric) approach.

In our model, cerebral ischemia produced a significant decrease in the spleen marginal zone diameter in the ischemic versus the control group. N-3 PUFA rich fish-oil treatment ( $\mathrm{T}$ group) reversed this shift, reestablishing the normal size of the marginal zone, but did not affect the histological architecture. This finding is consistent with the data obtained by another research team who reported that diet with a low n6/n-3 PUFA ratio does not influence the histology and ultrastructure of the spleen [38]. Since the reduction of the marginal zone might be related to immunosuppression met under ischemic conditions [41], the 
restoration seen in n-3 PUFA preconditioning might have a protective significance.

Stroke provokes systemic inflammation that alters the regulation of bone marrow hematopoietic stem cells, increasing also the export of granulocytes and monocytes to peripheral tissues. Recently, it was described, that in healthy mice n-3 PUFA rich diets stimulate the extra-medullary granulopoiesis [39]. Characterizing the morphological and quantitative changes in the extra-medullary hematopoietic microenvironment, we found an abundance of hematopoietic and especially myeloperoxidase-positive granulopoietic progenitors in the ischemic group (I) compared with sham and FO preconditioned groups. We consider these are not contradictory results, since polyunsaturated fatty acids, like EPA and DHA, might act as inhibitors of excessive granulopoiesis in acute ischemic conditions. Peripheral monocytes/macrophages were shown to infiltrate the damaged brain tissue in a chemokine ligand 2 (CCL-2) dependent manner and contribute to post-stroke cerebral inflammation and perpetuation of brain injury. There are relatively little literature data focused on monocyte/macrophage activation in the spleen and mobilization from the periphery to brain infarction [21, 23]. The activated monocytes/macrophages can follow separate routes of activation, being defined as either classical (M1) or alternative (M2). These cells act differently on target tissues: the M1 subtype is proinflammatory, generating reactive oxygen species, while the M2 phenotype contributes to the release of anti-inflammatory cytokines and mediates tissue repair $[5,40]$. There are no absolute specific phenotypic markers of M1- and M2-type macrophages, however, reported candidates are Ly6G, CD16/32, iNOS 2 for M1 and CD163, CD206, Arg1 for M2 [20, 29, 32]. Analytical approaches based on the detection of the two functionally related arginine-specific enzymes: iNOS2 and Arg1 are promising. While the former synthesizes nitric oxide and citrulline from arginine, the latter hydrolyses the same substrate into ornithine and urea, making it unavailable for nitric oxide synthesis [29].

We investigated the presence of iNOS2 and Arg1positive cells in our specimens and found that iNOS2 shows a stronger expression in the ischemic group, while the FO preconditioning causes a significant M1/M2-phenotype shift in the favour of Arg1 in the white-pulp/red-pulp interface of the spleen. Even though iNOS2 and Arg1 positivity are numerically reduced, neuroprotective M2 type macrophages were dominant in the spleens of animals treated with n-3 polyunsaturated fatty acids, and the shift in the M2/M1 type ratio might be of high importance. M2 type macrophages were reported to scavenge cellular debris, to favourize cellular regeneration and tissue repair in the ischemic brain [14].

We recently reported the presence of Arg1 positive M2 type cells in the brain of a tMCAO rat model and showed that they are significantly elevated in the penumbra zone in comparison with the ischemic core [16]. Accordingly, splenic Arg1 positive macrophages contribute to the invasion of the damaged brain regions and might be a potential cellular target in immunomodulatory therapies.

It should be emphasized that the results described in this animal model cannot be directly translated to regulatory mechanisms that interplay in human ischemia because in the rodents' spleen, many factors like the species and age may influence the post-ischemic splenic morphology $[10,24]$.

\section{Conclusions}

In our study, ischemia and fish-oil treatment proved to cause only mild, non-significant splenic volume variations. However, cerebral ischemia triggered welldefined changes in the structure of the spleen. The diameter of the splenic marginal zone increased 24 hours after the onset of cerebral ischemia but turned back to normal size in the fish-oil treated animals. FO treatment exerted flagrant effects on extramedullar haematopoiesis enhancing the myeloid hyperplasia. Ischemia also increased the presence of iNOS2 positive, M1 type monocytes/macrophages, while FO treatment induced especially the Arg1 positive M2 subtype. Polyunsaturated fatty acids generated a significant shift in the M2/M1 cell ratio in the treatment group, in comparison with controls and ischemic rats. This is an important result, since the M2 type monocytes/ macrophages are protective cell types, and could be potential therapeutical targets in stroke.

\section{Acknowledgement}

This research was supported by an Internal Research Grant of the University of Medicine, Pharmacy, Science and Technology of Târgu Mureș, Romania (No. $17803 / 1 / 22.12 .2015)$ and partly funded by Studium Prospero Foundation, Romania (No. 1547/18.12.2015). The morphological analyses used the infrastructure of the Advanced Medical and Pharmaceutical Research Centre of the University of Medicine, Pharmacy, Science and Technology of Târgu-Mureș, Romania. The authors would like to thank Genoveva Rigmanyi for technical assistance.

\section{Conflict of interest}

The authors declare that they have no conflicts of interests.

\section{References}

1. Ajmo CTJr, Vernon DO, Collier L, Hall AA, GarbuzovaDavis S, Willing A, Pennypacker KR, The spleen contributes to stroke-induced neurodegeneration. $J$ Neurosci Res., 2008; 86(10): 2227-2234. 
2. Bao Y, Kim E, Bhosle S, Mehta H, Cho S, A role for spleen monocytes in post-ischemic brain inflammation and injury. $J$ Neuroinflammation, 2010; 7: 92: 1-6.

3. Belayev L, Khoutorova L, Atkins KD, Bazan NG, Robust docosahexaenoic acid-mediated neuroprotection in a rat model of transient, focal cerebral ischemia. Stroke, 2009; 40(9): 3121-3126.

4. Bu J, Dou Y, Tian X, Wang Z, Chen G, The Role of Omega-3 Polyunsaturated Fatty Acids in Stroke. Oxid Med Cell Longev., 2016: 2016: 6906712: 1-8.

5. Cai W, Liu S, Hu M, Sun X, Qiu W, Zheng S, Hu X, Lu Z, Post-stroke DHA Treatment Protects Against Acute Ischemic Brain Injury by Skewing Macrophage Polarity Toward the M2 Phenotype. Transl Stroke Res., 2018; 9(6): 669-680.

6. Cesta MF, Normal structure, function, and Histology of the spleen. Toxicol Pathol., 2006; 34: 455-465.

7. Ceulemans AG, Zgavc T, Kooijman R, Hachimi-Idrissi $\mathrm{S}$, Sarre S, Michotte Y, The dual role of the neuroinflammatory response after ischemic stroke: modulatory effects of hypothermia. J Neuroinflammation, 2010; 1(7): 74: 1-18.

8. Chauhan A, Al Mamun A, Spiegel G, Harris N, Zhu L, McCullough LD, Splenectomy protects aged mice from injury after experimental stroke. Neurobiol Aging, 2018; 61: 102-111.

9. Chauveau F, Cho TH, Perez M, Guichardant M, Riou A, Aguettaz P, Picq M, Lagarde M, Berthezène Y, Nighoghossian N, Wiart M, Brain-targeting form of docosahexaenoic acid for experimental stroke treatment: MRI evaluation and anti-oxidant impact. Curr Neurovasc Res., 2011; 8(2): 95-102.

10. Cheung HT, Nadakavukaren MJ, Age-depended changes in the cellularity and ultrastructure of the spleen of Fischer F344 rats. Mech Ageing Dev., 1983; 22: 22-33.

11. Cutuli D, De Bartolo P, Caporali P, Laricchiuta D, Foti F, Ronci M, Rossi C, Neri C, Spalletta G, Caltagirone C, Farioli-Vecchioli S, Petrosini L, n-3 polyunsaturated fatty acids supplementation enhances hippocampal functionality in aged mice. Front Aging Neurosci., 2014; 6: 220: 1-17.

12. Cutuli D, Pagani M, Caporali P, Galbusera A, Laricchiuta D, Foti F, Neri C, Spalletta G, Caltagirone C, Petrosini L, Gozzi A, Effects of Omega-3 Fatty Acid Supplementation on Cognitive Functions and Neural Substrates: A VoxelBased Morphometry Study in Aged Mice. Front Aging Neurosci., 2016; 8: 38: 1-14.

13. de Mello AH, Uberti MF, de Farias BX, de Souza NAR, Rezin GT, n-3 PUFA and obesity: from peripheral tissues to the central nervous system. Br J Nutr., 2018; 119(11): 1312-1323.

14. Fumagalli S, Perego C, Pischiutta F, Zanier ER, de Simoni MG, The ischemic environment drives microglia and macrophage function. Front Neurol., 2015; 6: 81: 1-19.

15. Gelderblom M, Leypoldt F, Steinbach K, Behrens D, Choe CU, Siler DA, Arumugam TV, Orthey E, Gerloff C, Tolosa E, Temporal and spatial dynamics of cerebral immune cell accumulation in stroke. Stroke, 2009; 40(5): 1849-1857.

16. Horváth E, Huțanu A, Chiriac L, Dobreanu M, Orădan A, Nagy EE, Ischemic damage and early inflammatory infiltration are different in the core and penumbra lesions of rat brain after transient focal cerebral ischemia. $J$ Neuroimmunol., 2018; 324: 35-42.

17. Hu X, Zhang F, Leak RK, Zhang W, Iwai M, Stetler RA, Dai Y, Zhao A, Gao Y, Chen J, Transgenic overproduction of omega-3 polyunsaturated fatty acids provides neuroprotection and enhances endogenous neurogenesis after stroke. Curr Mol Med., 2013; 13(9): 1465-1473.

18. Hutanu A, Horváth E, Orădan A, Voidăzan S, Chiriac L, Muntean DL, Dobreanu M, Fish-oil preconditioning modulates plasma MCP-1 and TIMP-1 levels after experimental induced transient cerebral ischemia. Farmacia, 2018; 64(4): 602-608.

19. Jin R, Yang G, Li G, Inflammatory mechanisms in ischemic stroke: role of inflammatory cells. $J$ Leukoc Biol., 2010; 87(5): 779-789.

20. Kanazawa M, Ninomiya I, Hatakeyama M, Takahashi T, Shimohata T, Microglia and monocytes/macrophages polarization reveal novel therapeutic mechanism against stroke. Int J Mol Sci., 2017; 18(10): 2135: 1-18.

21. Kim E, Yang J, Beltran CD, Cho S, Role of spleenderived monocytes/macrophages in acute ischemic brain injury. J Cereb Blood Flow Metab., 2014; 34(8): 1411-1419.

22. Lalancette-Hébert M, Julien C, Cordeau P, Bohacek I, Weng YC, Calon F, Kriz J, Accumulation of dietary docosahexaenoic acid in the brain attenuates acute immune response and development of postischemic neuronal damage. Stroke, 2011; 42(10): 2903-2909.

23. Liu ZJ, Chen C, Li FW, Shen JM, Yang YY, Leak RK, Ji XM, Du HS, Hu XM, Splenic response in ischemic stroke: new insights into stroke pathology. CNS Neurosci Ther., 2015; 21(4): 320-326.

24. Losco P, Normal development, growth and aging of the spleen. In: Pathobiology of the aging rat. Mohr U, Dungworth DL, Capen CC (eds). ILSI Press, Washington DC, 1992; 75-94.

25. Makarewicz-Wujec M, Parol G, Parzonko A, KozłowskaWojciechowska M, Supplementation with omega-3 acids after myocardial infarction and modification of inflammatory markers in light of the patients' diet: a preliminary study. Kardiol Pol., 2017; 75(7): 674-681.

26. Orădan A, Hutanu A, Horváth E, Chiriac L, Dobreanu $\mathrm{M}$, Improved rat stroke model by intraluminal middle cerebral artery occlusion: a special emphasis on surgical technique. Health Problems of Civilisation, 2017: 11(3): 202-210.

27. Orr SK, Trépanier MO, Bazinet RP, n-3 Polyunsaturated fatty acids in animal models with neuroinflammation. Prostaglandins Leukot Essent Fatty Acids, 2013; 88(1): 97-103.

28. Pan HC, Kao TK, Ou YC, Yang DY, Yen YJ, Wang $\mathrm{CC}$, Chuang YH, Liao SL, Raung SL, Wu CW, Chiang AN, Chen CJ, Protective effect of docosahexaenoic acid against brain injury in ischemic rats. $J$ Nutr Biochem., 2009; 20(9): 715-725.

29. Rath M, Müller I, Kropf P, Closs EI, Munder M, Metabolism via Arginase or Nitric Oxide Synthase: two competing arginine pathways in macrophages. Front Immunol., 2014; 5: 532: 1-10.

30. Seifert HA, Hall AA, Chapman CB, Collier LA, Willing $\mathrm{AE}$, Pennypacker KR, A transient decrease in spleen size following stroke corresponds to splenocyte release 
into systemic circulation. J Neuroimmune Pharmacol., 2012; 7(4): 1017-1024.

31. Serini S, Cassano R, Corsetto PA, Rizzo AM, Calviello G, Trombino S, Omega-3 PUFA Loaded in ResveratrolBased Solid Lipid Nanoparticles: Physicochemical Properties and Antineoplastic Activities in Human Colorectal Cancer Cells In Vitro. Int J Mol Sci., 2018; 19(2): 586: 1-19.

32. Sica A, Erreni M, Allavena P, Porta C, Macrophage polarization in pathology. Cell Mol Life Sci., 2015; 72(21): 4111-4126.

33. Silva AR, Kriguer-Júnior RJ, Serigiolle LC, Gomes HM, Rodrigues DA, Leme PL, Increase in spleen volume of rats on experimental model of pre-hepatic portal hypertension. Arq Bras Cir Dig., 2013; 26(3): 206-212.

34. Soni NK, Ross AB, Scheers N, Savolainen OI, Nookaew I, Gabrielsson BG, Sandberg AS, Splenic Immune Response Is Down-Regulated in C57BL/6J Mice Fed Eicosapentaenoic Acid and Docosahexaenoic Acid Enriched High Fat Diet. Nutrients, 2017; 9(1): 50: $1-17$.

35. Tarța-Arsene O, Leanca M, Dica A, Bran E, Rad F, Timnea O, Păcurar D, Velescu BȘ, Nicolae AC, Drăgoi CM, Dietary omega-3 fatty acids supplimentation for attention deficit with hyperactivity disorder in epileptic children. Farmacia, 2017; 65(4): 550-556.

36. The World Health Organization (WHO) (2017) updates fact sheet on Top 10 causes of Death. https://community medicine4asses.wordpress.com/2017/02/01/whoupdates-fact-sheet-on-top-10-causes-of-death-27january-2017/

37. Vahidy FS, Parsha KN, Rahbar MH, Lee M, Bui TT, Nguyen C, Barreto AD, Bambhroliya AB, Sahota P, Yang B, Aronowski J, Savitz SI, Acute splenic responses in patients with ischemic stroke and intracerebral hemorrhage. J Cereb Blood Flow Metab., 2016; 36(6): 1012-1021.

38. Wang MZ, Ding LY, Gao J, Wang JF, Zhou G, Zhang J, Effects of dietary n-6/n-3 polyunsaturated fatty acid ratios on the mass and histological and ultrastructures of liver, spleen and thymus of 70-day-old Yangzhou goslings. J Anim Physiol Anim Nutr (Berlin), 2016; 100(2): 391-400.

39. Xia S, Li XP, Cheng L, Han MT, Zhang MM, Shao QX, Xu HX, Qi L, Fish oil-rich diet promotes hematopoiesis and alters hematopoietic niche. Endocrinology, 2015; 156(8): 2821-2830.

40. Xiong XY, Liu L, Yang QW, Functions and mechanisms of microglia/macrophages in neuroinflammation and neurogenesis during stroke. Prog Neurobiol., 2016; 142: 23-44.

41. Yan FL, Zhang JH, Role of the sympathetic nervous system and spleen in experimental stroke-induced immunodepression. Med Sci Monit., 2014; 20: 24892496.

42. Zhang BJ, Men XJ, Lu ZQ, Li HY, Qiu W, Hu XQ, Splenectomy protects experimental rats from cerebral damage after stroke due to anti-inflammatory effects. Chin Med J (Engl.), 2013; 126(12): 54-60.

43. Zhang W, Wang H, Zhang H, Leak RK, Shi Y, Hu X, Gao Y, Chen J, Dietary supplementation with omegapolyunsaturated fatty acids robustly promotes neurovascular restorative dynamics and improves neurological functions after stroke. Exp Neurol., 2015; 272: 170-180.

44. Zhang W, Zhang H, Mu H, Zhu W, Jiang X, Hu X, Shi Y, Leak RK, Dong Q, Chen J, Gao Y, Omega-3 polyunsaturated fatty acids mitigate blood-brain barrier disruption after hypoxic-ischemic brain injury. Neurobiol Dis., 2016; 91: 37-46. 